\title{
UM INTELECTUAL ADMIRÁVEL
}

\section{Brasilio Sallum Jr.}

A morte inesperada de Gildo Marçal Brandão produziu em muitos de nós certo desconsolo com a fragilidade de nossa presença no mundo dos viventes. As muitas manifestações de apreço que sua morte desencadeou mostram que, enquanto viveu, o fez com força invejável. Elas revelam, cada uma a sua maneira, um pouco das marcas duradouras que a personalidade vigorosa de Gildo deixou nos seus circunstantes - alunos, colegas, companheiros de lutas, amigos e familiares.

Depois de mais de vinte anos de amizade fraterna e cada vez mais próxima, em que tecemos elos intelectuais, políticos e pessoais, não consigo encontrar palavras para expressar bem o afeto e a admiração que tinha por ele. Vou me limitar aqui a dizer dele como intelectual.

Já o admirava por isso antes mesmo de conhecê-lo pessoalmente. Lembro do entusiasmo com que li e reli o seu artigo 'Totalidade e Determinação Econômica”, muito instigante, luckacsiano, publicado em 1977, no primeiro número da revista Temas de Ciências Humanas. Quando o conheci já estava às voltas com a pesquisa sobre o Partido Comunis- 
ta, com que obteria o doutorado. Era, sem dúvida, talhado para o trabalho intelectual, embora não o entendesse como dissociado da política, quer dizer, das lutas entre forças sociais pela definição dos destinos da sociedade. Neste sentido, macroscópico, a política o atraía fortemente. A escolha dos temas de pesquisa, dos problemas a investigar e da forma de analisá-los indicam que nunca exerceu fria e asceticamente sua vocação intelectual. Mesmo quando se debruçava sobre assuntos do passado, o fazia apaixonadamente. Mais que isso, nos seus textos mais importantes sobressai a ousadia de sua reflexão sobre os fenômenos políticos. Uma reflexão que assumia os riscos de desafiar o mainstream da sua disciplina - a Ciência Política - e de defender racional e vigorosamente uma perspectiva de análise, inspirada no marxismo hegeliano, que rompesse o isolamento ascético do fenômeno examinado para reconstituir seus elos com o processo histórico e suas tendências imanentes de desenvolvimento. É o que ele propugna neste verdadeiro manifesto intelectual que é "Teoria Política a partir do Sul da América”, último capítulo de Linhagens do pensamento político brasileiro. Aí se encontra a retomada refletida e, por isso, nuançada, de antigas convicções contrárias ao "esquartejamento do real" e à autonomia do método em relação ao objeto, pois compreendia os conceitos como dependentes do processo histórico-social em seu conjunto. Reconhece, é claro, realisticamente, o caráter inevitável das especializações e o peso das instituições na conformação separada das disciplinas, mas - este é o ponto sublinhado - isso não justifica a apropriação fragmentada do objeto, cada pedaço correspondendo a uma disciplina própria. Não havendo como ignorar a divisão disciplinar, ele tratava de relativizá-la, de transcendê-la na direção de um horizonte pluridimensional que, longe de ser utópico, - ele assegurava - é permanentemente atualizado pela exigência, própria do movimento do objeto, de implosão das fronteiras disciplinares. Ele desen- 
volve argumento cerrado em favor disso e de muito mais, inclusive o diálogo e mesmo a aliança - contra o cientificismo - entre ciências sociais e filosofia.

Não se veja nesta orientação teórico-metodológica cuja exposição simplificada não faz justiça à elaborada pelo próprio Gildo - um receituário feito por quem nunca pôs a mão na massa. A leitura dos seus escritos principais - sobre o partido comunista e sobre o pensamento político-social brasileiro - revela que ele seguia aquela orientação com maestria. Veja-se, por exemplo, o seu A esquerda positivaestudo brilhante sobre a esquerda comunista brasileira no período 1920-1964.

Nele, Gildo examina a experiência comunista não apenas no interior das atividades políticas mas também explora suas conexões com a diferenciação das classes sociais e a expansão capitalista no Brasil. Ao examinar as conexões do seu objeto específico com o desenvolvimento da sociedade global, ele tornava mais difícil sua empreitada, mas os resultados mostram ganhos notáveis em qualidade. É o que salta aos olhos quando apresenta e examina - de forma vigorosa e polêmica - as três hipóteses sobre o seu objeto - a presença do PCB na vida política brasileira.

A primeira delas é que, do mesmo modo que o capitalismo no Brasil, a classe operária é de formação hipertardia, só tendo gerado formas de autoconsciência na medida em que o capitalismo "verdadeiro", isto é, industrial se foi implantando entre nós. Esta afirmação, que parece óbvia de um ponto de vista materialista (toda a forma de consciência tem suas bases materiais), contraria fortemente a maior parte da literatura sobre as formas de organização da classe operária, que descreve a história operária como tendo um ápice na Primeira República e uma trajetória de decadência a partir dos anos 1930. Para Gildo, ao contrário, só nos anos 1950 - quando o capitalismo industrial começa a se integrar nacionalmente - seria pertinente o debate 
sobre estar ou não o operariado se constituindo em classe politicamente autônoma. Dessa forma, mesmo que os agentes só pela consciência possam transformar-se em sujeitos históricos, trata-se sempre de consciência da objetividade, não cabendo falar em autonomia política da classe operária em períodos da história brasileira em que ela mesma sequer fora produzida pelo capital.

Seguindo esta orientação, ele avalia cuidadosa, mas severamente a literatura acadêmica que faz apologia do sindicalismo das minorias militantes, de orientação anarquista, que dominava o movimento operário antes de 1930. Não há, diz ele, "que confundir combatividade, resistência e grandeza moral com significação histórico-universal; nem as lutas cotidianas e a natural resistência da classe operária à escravização que o sistema de salariado e a existência do Estado implicam, com a constituição de sujeito político". Mais: a estrutura sindical montada pelo movimento anarquista seria mais produto que premissa das agitações políticas da época, e as grandes greves de 1917 e 1919 seriam antes manifestações de desespero e isolamento do que de maturidade e capacidade de articulação e defesa dos interesses da classe operária. E para completar, no pós-1930, longe de decaírem politicamente, "pela primeira vez os trabalhadores aparecem como classe nacionalmente configurada, ainda que reconhecida e posta como tal "pelo alto"'. O que, de todo modo, teria as implicações já apontadas há muito por Weffort: de 1930 em diante o sistema político dominante não poderá se desenvolver sem alguma forma de consentimento ativo dos "de baixo".

Sua segunda hipótese é de que o terreno privilegiado para a construção da identidade da classe operária é o partido político, a relação com o Estado e a política institucionalmente considerada. Com isso, Gildo opõe-se à literatura que tende a reconhecer a classe operária só na vida sindical, nos movimentos de resistência à hierarquia e disciplina 
fabris, nas greves. Confronta a literatura que tenta isolar o campo do fazer-se do campo do poder, como se pudesse isolar o instituinte do instituído, como se fosse possível isolar história do movimento operário e o movimento geral da sociedade e fazer história autorreferida do movimento operário. Do seu ponto de vista, a forma do processo político vigente condiciona os próprios modos de ser da classe e da luta de classes e, assim, o sujeito classe operária não se constituiria anteriormente à sua participação nas instituições.

Nesse passo, Gildo desenvolve discussão brilhante sobre o significado da ilegalidade do Partido Comunista durante a República Liberal (1946-1964) e introduz uma interpretação ousada e inovadora daquele regime. Na medida em que o processo político mais inclusivo condiciona o modo de ser operário e se introjeta no seu interior, a ilegalidade do PC é "variável forte para explicar a subalternidade operária durante a República liberal”. Desta forma, a fraqueza política e ideológica do proletariado brasileiro não resultaria principalmente do caráter retardatário da industrialização, da heterogeneidade estrutural da classe operária ou da orientação política desastrada de seus dirigentes. Para ele, o veto à participação política legal das classes subalternas, o impedimento à representação própria - proibição inerente ao regime político de 1946 - teria funcionado como um impedimento estratégico à formação de uma classe operária autônoma, tornando difícil e lento o processo de formação de sua consciência política.

Ademais, ele sugere que a exclusão política do PC condicionou, junto com a hipertrofia do Executivo, a evolução política dos partidos no período 1946-1964. A ausência de um enfrentamento sistemático com uma organização política vinculada às classes subalternas teria dado uma sobrevida aos partidos de notáveis, insulados na vida parlamentar. Restringindo a competição, a marginalização do PC teria contribuído, enfim, para bloquear a diferenciação e conso- 
lidação do sistema político-partidário. De forma mais geral, a ilegalidade do PC e, com isso, o veto à participação política legal das classes subalternas, é um índice importante do caráter limitado da democracia de 1946 e indica que a subalternidade operária era essencial ao tipo de Estado montado a partir de 1930.

A demonstração das duas hipóteses tem consequências fortes sobre a avaliação da ação e ideologia do Partido Comunista: de início, não havia suporte material - social e econômico - para a autonomia do partido e, quando ele apareceu, a ilegalidade restringiu sua arena de luta possível.

Ainda assim, mesmo não havendo muito que esperar do Partido Comunista, Gildo avança uma terceira hipótese, sobre o conteúdo ideológico e orientação política de suas opções. A hipótese é que "a especificidade do comportamento ideológico e da ação do PG foi sua incapacidade (ou impossibilidade) de optar definitivamente entre uma 20 via revolucionária e uma via reformista, [...] tendo em consequência atraído segmentos distintos da população com motivações diversas". Desta forma, "a contradiçào entre civilistas e militaristas, [que] permeia toda a história do PC e da esquerda política brasileira, [...] não se reduz à origem militar ou civil de seus dirigentes. Ao contrário tem a ver com a concepção de fazer política: politicista ou insurrecional”.

Chegamos aqui à ideia, enunciada no subtítulo do livro, de que o Partido Comunista era portador de duas almas, a de esquerda negativa, insurrecional e golpista, que concebe a revolução como explosão, e a de esquerda positiva, atenta à lógica inerente à vida política, que reconhece só poder alcançar o "objetivo final” por meio de objetivos intermediários e soluções "viáveis", que concebe a revolução como processo. Essas duas almas sempre conviveram conflitivamente no PCB: a alma de esquerda positiva teria dominado apenas por curtos períodos, nos ascensos de massa de 1942-1947 e 1958-1964; em geral, ela teria sido subjugada pelo vanguar- 
dismo, pelo golpismo e pelo aventureirismo. Exatamente o inverso, sublinhe-se, da imagem acomodada, conciliadora etc. que se tem feito do Partidão nos últimos decênios.

Como os qualificativos empregados para caracterizar a orientação predominante do PCB indicam, o juízo histórico do nosso Autor sobre sua atuação é bastante duro. Ela teria sido determinada "por uma leitura catastrofista da realidade, vale dizer, do capitalismo e da democracia" e pela ideia da iminência do socialismo que estaria embutida em todas as lutas econômico-sociais. Ou, à inversa, o modo dominante do PC fazer política desconheceria as condições objetivas do país, a especificidade do capitalismo que aqui se desenvolvia, desprezaria as instituições em geral, as instituições brasileiras em particular, a busca de objetivos intermediários e, sobretudo, a elaboração de soluções positivas para os problemas nacionais.

É claro que um juízo como este não diz respeito apenas ao PCB. Ele incide sobre as concepções vanguardistas que levaram a esquerda para a luta armada nos anos 1960 e 1970. A questão está fora do seu âmbito de estudo, mas ele se refere a isso, em nota, lembrando que outro momento realista da história do PC ocorreu na elaboração de uma política de frente popular de luta pela derrota política - e não derrubada, como pretendia a "esquerda revolucionária" - do regime militar. Com um mínimo de esforço, a discussão destes dilemas fornece instrumentos para avaliar os da esquerda de hoje, ainda que a ganga da ilegalidade não pese mais sobre ela e a alternativa de instaurar de imediato uma nova sociedade, socialista, tenha entrado para o reino das utopias.

Tenho plena consciência de que estas notas são esquemáticas e nem de longe fazem jus à complexidade e à riqueza do seu livro sobre o PCB e menos ainda ao conjunto do que Gildo nos legou. Elas são apenas testemunho de minha grande admiração por ele, amigo-irmão de quem espero, logo, sentir a saudade doce, em lugar do amargor da perda. 